\title{
A Study of Flu Epidemics in Portugal
}

\author{
Edgar Pereira1, Cecília Rosa ${ }^{2}$ \\ ${ }^{1}$ Department of Mathematics, Universidade Federal do Rio Grande do Norte, Natal, Brasil \\ ${ }^{2}$ Department of Mathematics, Instituto Politécnico da Guarda, Guarda, Portugal \\ Email: edgar@ccet.ufrn.br, cecirosa@ipg.pt
}

How to cite this paper: Pereira, E. and Rosa, C. (2019) A Study of Flu Epidemics in Portugal. Open Journal of Social Sciences, 7, 183-193. https://doi.org/10.4236/jss.2019.710015

Received: September 16, 2019

Accepted: October 12, 2019

Published: October 21, 2019

Copyright (C) 2019 by author(s) and Scientific Research Publishing Inc. This work is licensed under the Creative Commons Attribution International License (CC BY 4.0).

http://creativecommons.org/licenses/by/4.0/

\section{(c) (1) Open Access}

\begin{abstract}
We study the flu seasonal epidemics in Portugal in the last 20 years. Based on the analysis of historic data gathered from the official weekly reports we present some scenarios for the next 20 years.
\end{abstract}

\section{Keywords}

Flu Epidemic, Vaccination, Trend Line, Monotonic Behaviour, Periodic Behaviour

\section{Introduction}

The seasonal flu epidemic is one of the major social concerns of governments and health organizations due to the profound damage it causes yearly. Immunization by means of vaccination is the main tool against the epidemics. Seasonal influenza viruses occur in the Winter months, spreading from person-to-person. When a new type of virus appears, most people are not inoculated so these viruses may cause large outbreaks and that is when a pandemic occurs. Vaccines protect the population against seasonal influenza but not against a pandemic and when it happens a large number of casualties may occur. The last pandemic was in 2009 when a new strain of influenza A(H1N1) virus spread worldwide. Now the $\mathrm{A}(\mathrm{H} 1 \mathrm{~N} 1) 2009$ virus continues to circulate and it is considered a seasonal influenza [1].

Since 2009 the attention to vaccination has been reinforced and most of the countries in Europe are joining efforts to control the flu development. In Portugal a new surveillance system was implemented.

Mathematical tools including interpolation functions, trend lines and models permit the study of the behaviour of an infectious disease with the objective of supporting the measures of the health organisms that deal with spread and control. With these mathematical tools, it is also possible to perform simulations 
that can give important information for policies to be used in the near future and also for the following years [2] [3].

This paper is organized as follows. In Section 2 the importance of vaccination is outlined, a description of influenza virus types is done and the national Portuguese health organisms related to prevention and control of the flu are referred to. Section 3 has the historic data of the seasons 1999/2000 to 2018/2019. In Section 4 some scenarios for the next 20 years are presented, where monotonic and periodic behaviours are considered. Section 5 has the conclusions and possible further studies.

\section{Vaccination}

The development of vaccines in laboratories started in the late 19th century and in the 20th century it has spread to become the main tool to combat epidemics and nowadays molecular biology permits highly sophisticated development of vaccines [4].

Influenza viruses are of two types: A and B. Moreover, type A has subtypes based on the antigens HA and NA. Since 1977 the types A(H1N1), A(H3N2) viruses, and $B$ influenza viruses have co-circulated globally. Each year new variants of influenza virus emerge due to the frequent antigenic change leading to the need of repeating vaccination yearly. When a new subtype of virus appears, there is no immunity among humans leading to a pandemic ("an uncontrolled epidemic"). In 2009 a novel influenza A(H1N1) virus caused a worldwide pandemic [5].

Each year the World Health Organization (WHO) recommend viruses for inclusion in influenza vaccines, in February for the northern hemisphere and in September for the southern hemisphere. This recommendation for annual vaccination is due to the mutation of influenza virus. In Portugal the influenza season lasts from the 40th week of one year to the 20th week of the next year [6].

In Portugal the National Influenza Surveillance Program (PNVG) ensures integrated clinical and laboratory monitoring of influenza, which is done by some organizations in coordination with European Union (EU) countries. The surveillance networks that support the PNVG by collecting biological samples and by providing clinical notifications are:

- Sentinel-Doctors network

- Emergency and Obstetric Services network

- EuroEVA doctors' network

- Portuguese Laboratory network for influenza diagnosis

- Intensive Care Unit network

The Sentinel-Doctors network is constituted by general practitioners, also referred to as family physicians, who work in Personalized Health Care Units (UCSP) or Family Health Units (USF) throughout continental Portugal and autonomous regions. These doctors have been collaborating in the surveillance of influenza since 1990, providing data both to the clinical and laboratorial components of the integrated surveillance system. Emergency and Obstetric Services 
network has doctors working in various institutions affiliated to the National Health Service and mostly contribute to the laboratorial component of the surveillance of influenza since they monitor the risk group of pregnant women. EuroEVA project is part of a multicentric European project-I-MOVE-Monitoring influenza vaccine effectiveness during influenza seasons and pandemics in the European Union, another one that deals with the clinical and laboratorial components of the integrated system of surveillance. The Portuguese Laboratory network for influenza diagnosis, a valuable asset to PNVG, comprises 18 laboratories with professionals that perform influenza diagnosis as well as other respiratory viruses in acute infection cases registered at hospitals in Portugal. Finally, the Intensive Care Unit network implemented in 2009 after the influenza pandemic, monitors serious cases of acute respiratory diseases occurring in patients admitted in Intensive Care Units [7] [8].

\section{Historic Data}

The flu surveillance in Portugal is active since October 1999 and it lasts from the 40th week (in October) from one calendar year to the 20th week (in May) of the next year, it comprises the Winter season where the flu epidemic spread.

The historic data presented here is available in several reports of the Instituto Nacional de Saúde Doutor Ricardo Jorge (INSA) in the web site http://www.insa.pt.

In Table 1 and Figure 1, we show the coverage of the seasonal influenza vaccination from the years $2001 / 2002$ to 2018/2019 [7] [9] [10] [11].

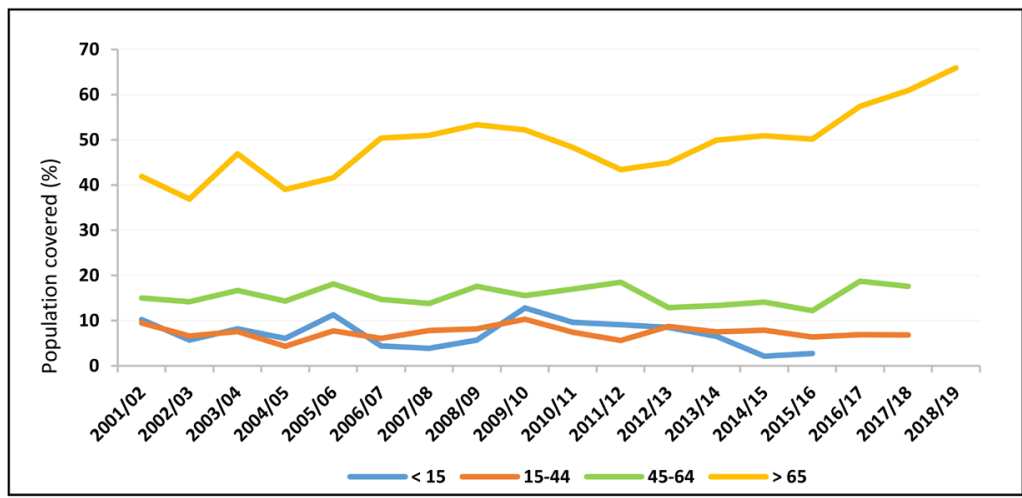

Figure 1. Evolution of the continent-resident population covered by seasonal anti-flu vaccine between 2001/2002 and 2018/2019, by age group (\%).

Table 1. Evolution of the continent-resident population covered by seasonal anti-flu vaccine between 2001/2002 and 2018/2019, by age group (\%).

\begin{tabular}{|c|c|c|c|c|c|c|c|c|c|c|c|c|c|c|c|c|c|c|}
\hline & $\begin{array}{c}2001 / \\
02\end{array}$ & $\begin{array}{c}2002 / \\
03\end{array}$ & $\begin{array}{c}2003 / \\
04\end{array}$ & $\begin{array}{c}2004 / \\
05\end{array}$ & $\begin{array}{c}2005 / \\
06\end{array}$ & $\begin{array}{c}2006 / \\
07\end{array}$ & $\begin{array}{c}2007 / \\
08\end{array}$ & $\begin{array}{c}2008 / \\
09\end{array}$ & $\begin{array}{c}2009 / \\
10\end{array}$ & $\begin{array}{c}2010 / \\
11\end{array}$ & $\begin{array}{c}2011 / \\
12\end{array}$ & $\begin{array}{c}2012 / \\
13\end{array}$ & $\begin{array}{c}2013 / \\
14\end{array}$ & $\begin{array}{c}2014 / \\
15\end{array}$ & $\begin{array}{c}2015 / \\
16\end{array}$ & $\begin{array}{c}2016 / \\
17\end{array}$ & $\begin{array}{c}2017 / \\
18\end{array}$ & $\begin{array}{c}2018 / \\
19\end{array}$ \\
\hline$<15$ & 10.2 & 5.7 & 8.2 & 6.1 & 11.3 & 4.4 & 3.9 & 5.7 & 12.8 & 9.6 & 9.1 & 8.5 & 6.5 & 2.1 & 2.7 & --- & 2.4 & --- \\
\hline $15-44$ & 9.5 & 6.6 & 7.6 & 4.3 & 7.7 & 6.1 & 7.8 & 8.2 & 10.3 & 7.4 & 5.6 & 8.7 & 7.5 & 7.9 & 6.4 & 6.9 & 6.8 & --- \\
\hline $45-64$ & 15 & 14.2 & 16.7 & 14.3 & 18.1 & 14.7 & 13.8 & 17.6 & 15.5 & 17 & 18.5 & 12.9 & 13.3 & 14.1 & 12.2 & 18.7 & 17.6 & --- \\
\hline$>65$ & 41.9 & 36.9 & 46.9 & 39 & 41.6 & 50.4 & 51 & 53.3 & 52.2 & 48.3 & 43.4 & 44.9 & 49.9 & 50.9 & 50.1 & 57.4 & 60.9 & 65.9 \\
\hline
\end{tabular}


In Figure 1, it can be observed that the vaccination rate in the all age cohorts is almost constant except in the elder population with age greater than 65 , in which this coverage is increasing, as the vaccine shots are free of charge for the elderly since the $2012 / 2013$ season.

The flu incidence number is shown next, in Table 2 and respective Figure 2, where we have the weekly data of the population flu incidence by 100,000 inhabitants [7] [12].

Table 2. Incidence rate of flu epidemics per 100,000 inhabitants from 1999/2000 to 2018/2019.

\begin{tabular}{|c|c|c|c|c|c|c|c|c|c|c|c|c|c|c|c|c|c|c|c|c|}
\hline Week/ & 1999/ & 2000/ & 2001/ & 2002/ & 2003/ & 2004/ & 2005/ & 2006/ & 2007/ & $2008 /$ & 2009/ & 2010/ & 2011/ & 2012/ & 2013/ & 2014/ & $2015 /$ & 2016/ & 2017/ & 2018/ \\
\hline Years & 00 & 01 & 02 & 03 & 04 & 05 & 06 & 07 & 08 & 09 & 10 & 11 & 12 & 13 & 14 & 15 & 16 & 17 & 18 & \\
\hline 40 & 15.5 & 5.6 & 13.5 & 17.3 & 16.8 & 5.5 & 15.7 & 7.5 & 16.0 & 12.3 & 15.4 & 4.1 & 0.0 & 0.0 & 0.0 & 8.2 & 2.5 & 7.7 & 16.3 & 3.6 \\
\hline 41 & 11.5 & 11.0 & 14.2 & 23.1 & 13.2 & 5.3 & 16.9 & 7.5 & 6.9 & 14.1 & 10.7 & 8 & 12.6 & 11.9 & 0.0 & 23.9 & 3.0 & 5.8 & 7.0 & 0.0 \\
\hline 42 & 14.5 & 13.1 & 5.8 & 25.3 & 26.1 & 11.8 & 9.9 & 8.3 & 10.0 & 13.3 & 26.5 & 5.6 & 17.5 & 15.4 & 7.7 & 7.7 & 3.2 & 10.7 & 11.9 & 5.5 \\
\hline 43 & 7.7 & 12.0 & 11.2 & 18.2 & 17.4 & 12.6 & 8.1 & 9.4 & 8.6 & 9.7 & 20.0 & 8.6 & 3.3 & 7.1 & 5.5 & 2.9 & 7.3 & 9.3 & 7.3 & 10.9 \\
\hline 44 & 14.8 & 12.6 & 14.9 & 20.3 & 44.5 & 27.8 & 13.5 & 3.7 & 2.1 & 13.8 & 50.8 & 10.8 & 7.7 & 14.9 & 4.4 & 2.5 & 10.3 & 16.7 & 6.1 & 6.1 \\
\hline 45 & 11.4 & 11.6 & 11.4 & 34.5 & 77.0 & 13.9 & 14.0 & 13.1 & 15.2 & 23.4 & 64.7 & 9.9 & 16.6 & 23.8 & 0.0 & 0.0 & 2.5 & 20.8 & 7.4 & 8.8 \\
\hline 46 & 10.4 & 16.4 & 21.0 & 30.8 & 152.5 & 19.1 & 14.5 & 6.4 & 23.9 & 34.5 & 119.3 & 16.5 & 16.1 & 23.1 & 5.8 & 5.6 & 9.6 & 27.3 & 17.1 & 7.6 \\
\hline 47 & 15.0 & 20.3 & 18.9 & 39.8 & 166.7 & 17.6 & 21.5 & 9.4 & 15.7 & 27.1 & 133.7 & 18.3 & 26.6 & 7.7 & 24.4 & 6.3 & 6.6 & 28.6 & 11.9 & 0.0 \\
\hline 48 & 19.3 & 20.5 & 16.5 & 53.2 & 111.9 & 15.6 & 11.5 & 11.7 & 13.5 & 23.4 & 88.6 & 25.8 & 22.1 & 15.2 & 6.8 & 18.5 & 8.5 & 48.1 & 20.3 & 7.9 \\
\hline 49 & 17.3 & 16.5 & 19.4 & 65.9 & 123.8 & 12.3 & 14.7 & 8.3 & 6.5 & 41.3 & 93.2 & 46.2 & 19.5 & 8.5 & 14.0 & 12.9 & 13.9 & 71.8 & 21.4 & 24.6 \\
\hline 50 & 15.0 & 18.5 & 18.0 & 77.0 & 100.8 & 28.1 & 18.3 & 10.3 & 15.1 & 80.9 & 67.2 & 79.5 & 37.0 & 3.4 & 9.1 & 11.5 & 8.5 & 81.6 & 22.4 & 6.6 \\
\hline 51 & 14.5 & 28.7 & 17.1 & 47.5 & 68.1 & 16.5 & 23.3 & 11.7 & 11.6 & 133.1 & 47.5 & 81.4 & 12.1 & 16.1 & 40.4 & 36.2 & 49.7 & 110.3 & 22.9 & 19.6 \\
\hline 52 & 13.2 & 36.9 & 25.6 & 49.1 & 63.4 & 50.6 & 31.3 & 29.4 & 11.6 & 0.0 & 45.2 & 121.1 & 14.4 & 0.0 & 17.3 & 32.0 & 23.0 & 87.8 & 78.8 & 28.0 \\
\hline 1 & 95.6 & 44.5 & 70.2 & 45.0 & 44.6 & 71.6 & 32.9 & 42.4 & 37.9 & 199.5 & 28.2 & 100.2 & 17.6 & 16.3 & 40.9 & 175.3 & 47.0 & 92.2 & 62.3 & 80.9 \\
\hline 2 & 117.6 & 39.1 & 95.4 & 32.7 & 42.5 & 149.3 & 21.9 & 31.7 & 30.1 & 95.5 & 10.8 & 72.6 & 37.5 & 38.7 & 45.7 & 133.3 & 44.3 & 50.8 & 49.3 & 48.8 \\
\hline 3 & 142.9 & 68.0 & 222.8 & 27.4 & 28.7 & 201.2 & 22.8 & 74.9 & 62.0 & 68.4 & 10.8 & 84.4 & 30.9 & 44.1 & 72.1 & 139.5 & 64.6 & 44.6 & 66.4 & 85.5 \\
\hline 4 & 156.6 & 48.8 & 226.6 & 25.7 & 19.0 & 162.5 & 21.9 & 120.1 & 52.6 & 46.8 & 9.5 & 63.3 & 57.6 & 63.5 & 88.3 & 160.6 & 54.7 & 36.2 & 61.1 & 89.3 \\
\hline 5 & 111.4 & 74.5 & 239.0 & 56.1 & 11.2 & 209.7 & 23.8 & 121.7 & 56.0 & 34.8 & 5.3 & 79.8 & 90.8 & 51.2 & 68.0 & 99.8 & 39.7 & 20.0 & 34.1 & 69.5 \\
\hline 6 & 66.4 & 40.5 & 167.6 & 30.3 & 13.2 & 148.8 & 31.8 & 122.4 & 52.3 & 28.7 & 10.0 & 47.8 & 77.9 & 39.7 & 66.4 & 89.2 & 46.2 & 24.5 & 29.9 & 40.9 \\
\hline 7 & 56.1 & 50.0 & 107.6 & 18.9 & 15.9 & 128.2 & 34.8 & 78.1 & 47.8 & 15.1 & 10.2 & 34.1 & 83.9 & 42.7 & 48.1 & 88.8 & 39.0 & 7.0 & 38.1 & 36.7 \\
\hline 8 & 34.2 & 32.9 & 71.6 & 28.5 & 17.0 & 74.9 & 26.3 & 49.7 & 36.2 & 14.5 & 5.2 & 37.6 & 137.0 & 58.4 & 48.1 & 39.8 & 40.4 & 6.4 & 28.1 & 43.9 \\
\hline 9 & 31.5 & 39.2 & 43.5 & 13.4 & 17.9 & 77.4 & 37.3 & 19.1 & 38.0 & 22.8 & 6.7 & 29.5 & 125.4 & 64.4 & 13.5 & 29.9 & 26.1 & 2.4 & 27.8 & 28.3 \\
\hline 10 & 11.8 & 30.2 & 57.2 & 14.0 & 10.4 & 56.3 & 23.3 & 16.4 & 26.0 & 9.4 & 4.3 & 21.9 & 137.7 & 69.6 & 13.9 & 12.7 & 13.9 & 2.6 & 17.5 & 42.7 \\
\hline 11 & 9.4 & 19.2 & 40.0 & 14.0 & 9.9 & 36.5 & 24.7 & 8.5 & 22.1 & 7. & 6.8 & 12.5 & 52.6 & 59.7 & 9.0 & 8.5 & 19.4 & 5.8 & 30.9 & 3.2 \\
\hline 12 & 6.4 & 24.1 & 29.5 & 16.7 & 6.0 & 19.1 & 28.2 & 1.9 & 13.2 & 12.1 & 3.8 & 2.3 & 41.6 & 37.7 & 9.7 & 4.5 & 10.8 & 0.0 & 5.3 & 8.5 \\
\hline 13 & 10.7 & 16.5 & 16.3 & 14.9 & 5.3 & 16.5 & 17.5 & 6.0 & 15.7 & 0.0 & 2.0 & 8.6 & 22.1 & 0.0 & 8.7 & 7.7 & 9.2 & 2.3 & 3.9 & 0.0 \\
\hline 14 & 0.0 & 0.0 & 0.0 & 0.0 & 7.4 & 13.0 & 5.1 & 1.9 & 0.0 & 4.0 & 2.3 & 2.3 & 26.2 & 31.3 & 10.6 & 4.9 & 22.2 & 2.6 & 11.6 & 0.0 \\
\hline 15 & 0.0 & 0.0 & 0.0 & 0.0 & 6.6 & 6.4 & 5.1 & 3.6 & 0.0 & 2.6 & 2.3 & 3.1 & 0.0 & 26.8 & 5.9 & 2.5 & 5.2 & 0.0 & 0.0 & 6.5 \\
\hline 16 & 0.0 & 0.0 & 0.0 & 0.0 & 6.5 & 6.3 & 8.8 & 2.4 & 0.0 & 5.3 & 0.0 & 0.0 & 7.9 & 3.2 & 6.3 & 0.0 & 4.1 & 0.0 & 4.5 & 0.0 \\
\hline 17 & 0.0 & 0.0 & 0.0 & 0.0 & 2.6 & 6.0 & 4.5 & 0.9 & 0.0 & 5.8 & 0.0 & 0.0 & 0.0 & 4.9 & 3.5 & 0.0 & 5.0 & 0.0 & 0.0 & 0.0 \\
\hline 18 & 0.0 & 0.0 & 0.0 & 0.0 & 0.0 & 3.9 & 3.4 & 6.6 & 0.0 & 9.7 & 0.0 & 0.0 & 7.7 & 0.0 & 0.0 & 0.0 & 3.2 & 0.0 & 0.0 & 0.0 \\
\hline 19 & 0.0 & 0.0 & 0.0 & 0.0 & 0.0 & 0.0 & 3.9 & 3.5 & 0.0 & 8.1 & 2.4 & 5.7 & 5.7 & 4.4 & 0.0 & 4.4 & 14.4 & 0.0 & 0.0 & 0.0 \\
\hline 20 & 0.0 & 0.0 & 0.0 & 0.0 & 0.0 & 0.0 & 0.0 & 0.0 & 0.0 & 6.4 & 4.8 & 0 & 0.0 & 0.0 & 3.5 & 0.0 & 0.0 & 2.9 & 0.0 & 0.0 \\
\hline
\end{tabular}




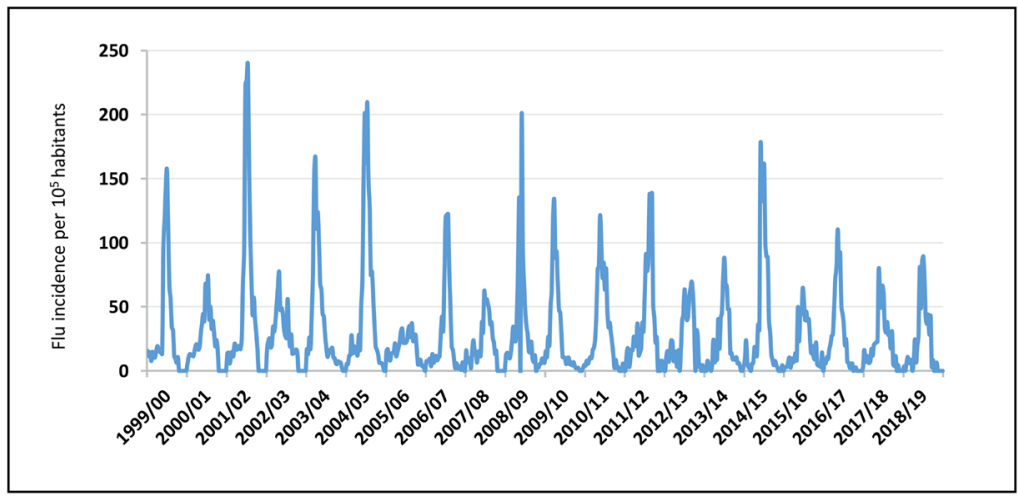

Figure 2. Flu incidence per 100,000 inhabitants from the season 1999/2000 to $2018 / 2019$.

The flu incidence reports are published weekly and in general a month later the respective definitive report is released [8]. In Table 3 and Figure 3 we can see that there is little discrepancy between them, which shows the importance of the weekly reports for the control and surveillance of the influenza epidemic.

Our analysis will be focused in the definitive weekly incidence reports according to Table 2 and Figure 2.

In Figure 4, we outline the seasonal behaviour in orange and a respective mean in blue, which is calculated by a logarithmic trend line of the maximum values of each year. We can observe that the mean is decreasing, which is a good indication that the control measures and programs of prevention and surveillance are working.

\section{The Coming Years}

Using the data present in Table 2 in Section 3 we give some scenarios for the flu incidence in Portugal for the next years. Our purpose is to make some projections based on the analysis of the reports in the last 20 years. The outlined tendencies are due to the use of different analysis criteria. A special tendency that can be observed is the cyclical behaviour, which is a very common phenomenon in the epidemic disease's history.

First, we consider monotone behaviour, that is always decreasing or always increasing. In Table 4 and respective Figure 5 and Figure 6, we project for the next 20 years the same behaviour observed in the last 20 years.

Table 3. Provisional and definitive maximum incidence rate of flu epidemics per 100,000 inhabitants from $1999 / 2000$ to 2018/2019.

\begin{tabular}{|c|c|c|c|c|c|c|c|c|c|c|c|c|c|c|c|c|c|c|c|c|}
\hline Jeelz/Yeare & 1999/ & $2000 /$ & 2001 & $2002 /$ & 2003/ & 2004/ & 2005 & $2006 /$ & $2007 /$ & $2008 /$ & 2009/ & 2010/ & 2011/ & 2012/ & 2013/ & |2014/ & 2015/ & $2016 /$ & |2017 & 2018 \\
\hline Week/Y ears & 00 & 01 & 02 & 03 & 04 & 05 & 06 & 07 & 08 & 09 & 10 & 11 & 12 & 13 & 14 & 15 & 16 & 17 & 18 & 19 \\
\hline $\begin{array}{c}\text { Definitive } \\
\text { maximum } \\
\text { data }\end{array}$ & 156.6 & 74.5 & 239 & 77 & 166.7 & 209.7 & 34.8 & 122.4 & 62 & 199.5 & 119.3 & 121.1 & 137.7 & 63.5 & 88.3 & 175.3 & 64.6 & 110.3 & 78.8 & 89.3 \\
\hline $\begin{array}{l}\text { Provisional } \\
\text { maximum } \\
\text { data }\end{array}$ & 93.5 & 129.3 & 239 & 41.1 & 105.6 & 163.1 & 31.4 & 31.4 & 60.4 & 142.3 & 136.4 & 109.7 & 164.8 & 69.6 & 80.7 & 148 & 59.4 & 113.3 & 58.4 & 89.3 \\
\hline
\end{tabular}


Table 4. Projections considering different scenarios for Flu incidence for the next 20 years.

\begin{tabular}{|c|c|c|c|c|c|c|}
\hline & Maximum & Mean at 4 years & Values $>100$ & Values $<100$ & First 10 years & Last 10 years \\
\hline 1999/00 & 160.5 & 144.4 & 201 & 60.7 & 148.1 & 256.4 \\
\hline $2000 / 01$ & 147.1 & 135.1 & 186.7 & 63.7 & 141.7 & 217.8 \\
\hline $2001 / 02$ & 139.2 & 129.6 & 178.3 & 65.4 & 138 & 195.3 \\
\hline $2002 / 03$ & 133.7 & 125.7 & 172.4 & 66.6 & 135.4 & 179.2 \\
\hline $2003 / 04$ & 129.3 & 122.7 & 167.8 & 67.5 & 133.3 & 166.8 \\
\hline $2004 / 05$ & 125.8 & 120.2 & 164.1 & 68.3 & 131.6 & 156.7 \\
\hline $2005 / 06$ & 122.8 & 118.1 & 160.9 & 69 & 130.2 & 148.1 \\
\hline $2006 / 07$ & 120.2 & 116.3 & 158.1 & 69.5 & 129 & 140.7 \\
\hline 2007/08 & 118.0 & 114.7 & 155.7 & 70 & 127.9 & 134.1 \\
\hline 2008/09 & 115.9 & 113.3 & 153.5 & 70.5 & 126.9 & 128.2 \\
\hline $2009 / 10$ & 114.1 & 112 & 151.6 & 70.9 & 126.1 & 122.9 \\
\hline 2010/11 & 112.4 & 110.8 & 149.8 & 71.3 & 125.3 & 118.1 \\
\hline 2011/12 & 110.8 & 109.7 & 148.1 & 71.6 & 124.5 & 113.6 \\
\hline $2012 / 13$ & 109.4 & 108.7 & 146.6 & 71.9 & 123.8 & 109.5 \\
\hline 2013/14 & 108.1 & 107.8 & 145.2 & 72.2 & 123.2 & 105.7 \\
\hline $2014 / 15$ & 106.8 & 106.9 & 143.9 & 72.5 & 122.6 & 102.1 \\
\hline $2015 / 16$ & 105.7 & 106.1 & 142.6 & 72.7 & 122 & 98.7 \\
\hline $2016 / 17$ & 104.6 & 105.3 & 141.4 & 73 & 121.5 & 95.5 \\
\hline 2017/18 & 103.5 & 104.6 & 140.3 & 73.2 & 121 & 92.5 \\
\hline 2018/19 & 102.5 & 103.9 & 139.3 & 73.4 & 120.6 & 89.6 \\
\hline $2019 / 20$ & 101.6 & 103.2 & 138.3 & 73.6 & 120.1 & 86.9 \\
\hline $2020 / 21$ & 100.7 & 102.6 & 137.3 & 73.8 & 119.7 & 84.3 \\
\hline $2021 / 22$ & 99.8 & 102 & 136.4 & 74 & 119.3 & 81.9 \\
\hline $2022 / 23$ & 99.0 & 101.4 & 135.5 & 74.2 & 118.9 & 79.5 \\
\hline $2023 / 24$ & 98.2 & 100.9 & 134.7 & 74.4 & 118.5 & 77.2 \\
\hline $2024 / 25$ & 97.4 & 100.3 & 133.9 & 74.5 & 118.1 & 75 \\
\hline $2025 / 26$ & 96.7 & 99.8 & 133.1 & 74.7 & 117.8 & 72.9 \\
\hline $2026 / 27$ & 96.0 & 99.3 & 132.3 & 74.9 & 117.5 & 70.9 \\
\hline $2027 / 28$ & 95.3 & 98.9 & 131.6 & 75 & 117.1 & 69 \\
\hline $2028 / 29$ & 94.7 & 98.4 & 130.9 & 75.2 & 116.8 & 67.1 \\
\hline 2029/30 & 94.0 & 97.9 & 130.2 & 75.3 & 116.5 & 65.2 \\
\hline $2030 / 31$ & 93.4 & 97.5 & 129.6 & 75.4 & 116.2 & 63.5 \\
\hline $2031 / 32$ & 92.8 & 97.1 & 128.9 & 75.6 & 115.9 & 61.8 \\
\hline $2032 / 33$ & 92.2 & 96.7 & 128.3 & 75.7 & 115.7 & 60.1 \\
\hline $2033 / 34$ & 91.7 & 96.3 & 127.7 & 75.8 & 115.4 & 58.5 \\
\hline $2034 / 35$ & 91.1 & 95.9 & 127.1 & 75.9 & 115.1 & 56.9 \\
\hline $2035 / 36$ & 90.6 & 95.6 & 126.6 & 76 & 114.9 & 55.4 \\
\hline $2036 / 37$ & 90.1 & 95.2 & 126 & 76.2 & 114.6 & 53.9 \\
\hline $2037 / 38$ & 89.6 & 94.8 & 125.5 & 76.3 & 114.4 & 52.5 \\
\hline $2038 / 39$ & 89.1 & 94.5 & 125 & 76.4 & 114.2 & 51.1 \\
\hline $2039 / 40$ & 88.6 & 94.2 & 124.5 & 76.5 & 113.9 & 49.7 \\
\hline
\end{tabular}


In Figure 5 the colors mean:

- Blue line is the continuation of blue line of Figure 4 where the season maxima of the incidences are considered;

- Pink line is the mean of the maxima at each interval of 4 years; this is done to correct discrepancies;

- Orange line indicates only the years with incidence values greater than 100 ;

- Green line indicates only the years with incidence values less than 100.

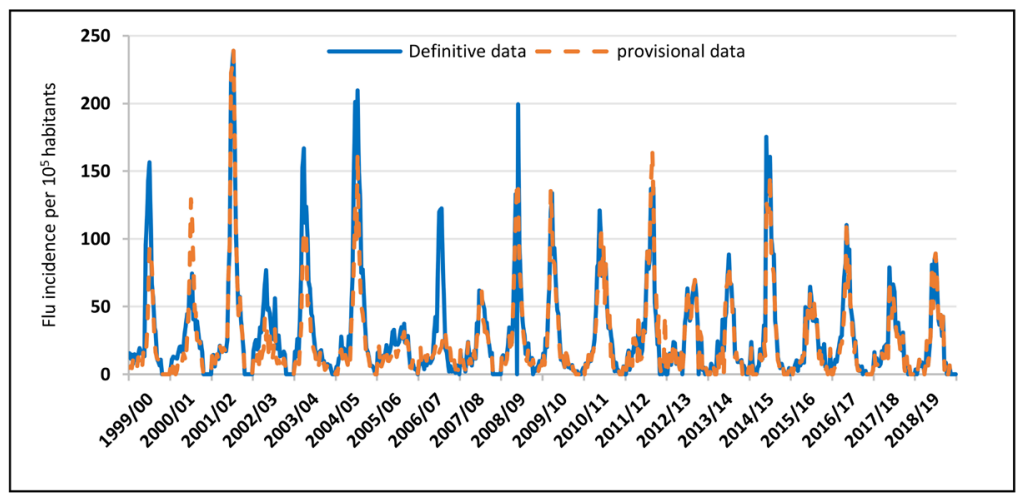

Figure 3. Provisional and definitive data of Flu incidence per 100,000 inhabitants from the season $1999 / 2000$ to $2018 / 2019$.

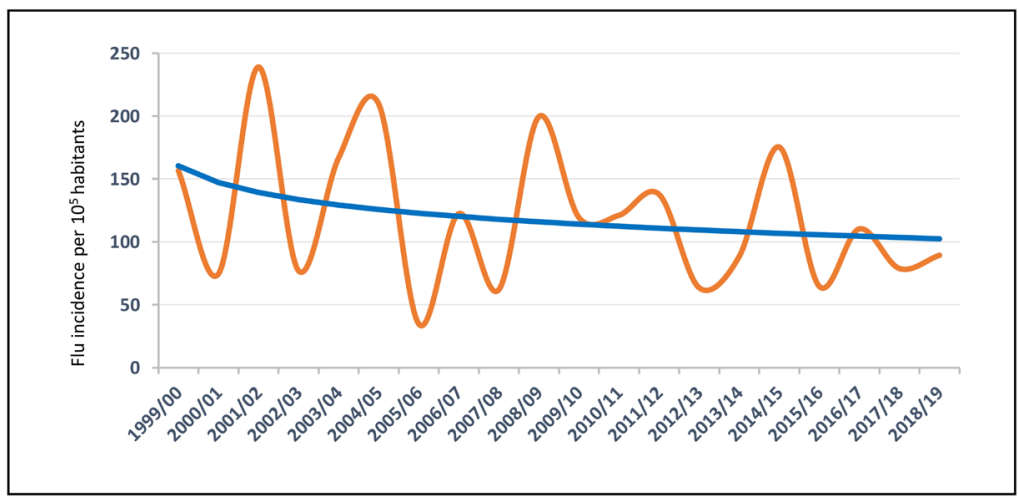

Figure 4. Flu incidence per 100,000 inhabitants and respective logarithm trend line from the season $1999 / 2000$ to $2018 / 2019$.

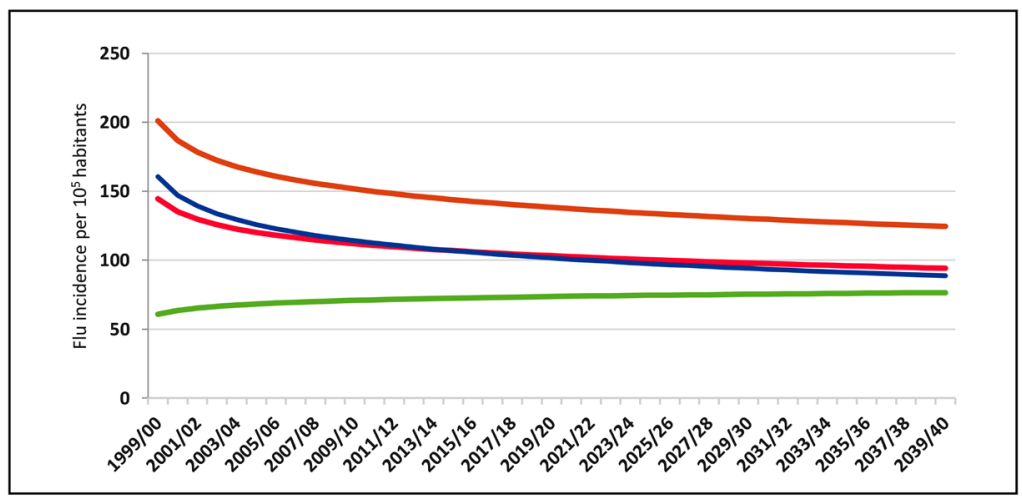

Figure 5. Extended trend lines of flu incidence per 100,000 inhabitants from the season 1999/2000 to 2039/2040 according to Table 4 . 


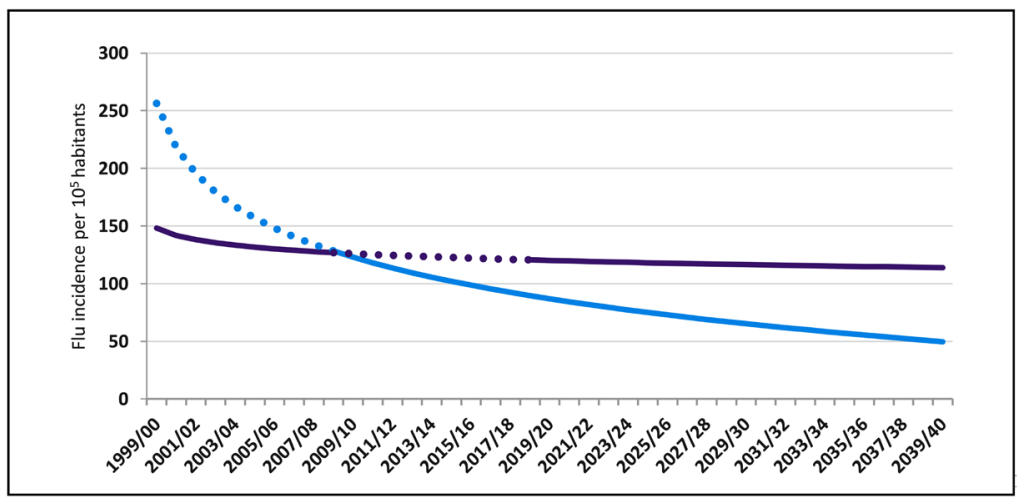

Figure 6. Extended trend lines of flu incidence per 100,000 inhabitants from the season 1999/2000 to 2039/2040 according to Table 4 .

In Figure 5, we observe that all lines are decreasing except the green one. Blue and yellow are very similar and all of them tend to stabilize. Although the green line has a slight increase it appears that it will also start decreasing in the future.

In Figure 6, the colors mean:

- In the purple line only the first 10 years of the interval, from 1999/2000 to 2008/2009, are considered;

- In the light blue line only the last 10 years of the interval, from 2009/2010 to 2018/2019, are considered.

In Figure 6, it is evident that the decrease is more significant in the last years. It is another good indication of the importance of the reinforcement of prevention and surveillance after 2009.

Next we study the occurrence of cyclic or periodic behaviour. We observe that among all the epidemics probably the flu is the best example of periodicity, due to its characteristic of seasonal spread during the Winter months, when the conditions are ideal for person-to-person contamination. An example of an epidemic that does not follow this very precise periodicity is the measles, whose recent worldwide outbreak appeared after 20 years. Even the dangerous Ebola has emerged from time to time in a way that is not yet well understood. In the case of the flu, despite the efforts in the development of prevention measures mainly through the vaccination, what is expected for a following year is another Winter season of flu outbreak, unless something really new occurs. We do not have enough information yet, but considering the recorded flu pandemics, it can also be observed a periodic repetition in the years 1918, 1957, 1968 and 2009, which are separated by alternated intervals of 50 and 10 years respectively.

Considering again Figure 2 we draw an upper line connecting the maximum of the years 1999/2000, 2001/2002, 2004/2005, 2006/2007, 2008/2009, 2014/2014 and 2018/2019, thus obtaining Figure 7.

It can be observed a periodic pattern in Figure 7 represented by two waves. This pattern can be continued, leading to a third wave lasting 20 years, from 2019/2020 to 2038/2039. This periodicity is showed in Figure 8 and it is ruled by: the wave height is decreased in $4 / 5$ and the length of the wave is doubled (times 2). 
It is possible to identify one more periodic pattern, which is shown in Figure 9, where the maxima of the years 1999/2000, 2001/2002, 2004/2005, 2006/2007, 2008/2009, 2011/2012, 2013/2014, 2014/2015 and 2018/2019 are connected.

Here, the pattern is not so evident but we still can propagate the waves for the next period of 20 years using waves of same respective lengths and obtaining the years maxima using the rate between the respective previous years. For example: to obtain the peak of fourth wave, the value $v(21)$ related to year 2021/2022, we use the years 2008/2009, 2001/2002 and 2014/2015 and compute

$$
v(21)=\left(\frac{v(08)}{v(01)}\right) v(14)
$$

The pattern for next 20 years is showed in Figure 10.

\section{Conclusion}

Influenza season typically goes from late Fall through early Spring of the next year, although in most cases infected people recover normally, influenza can cause several serious related illnesses. The main prevention measure is the annual vaccination to people of all ages. This is done yearly in Portugal and the reports both of this vaccination and of the flu incidence has been available for 20 years. In this work we study these reports and we make some forecast following

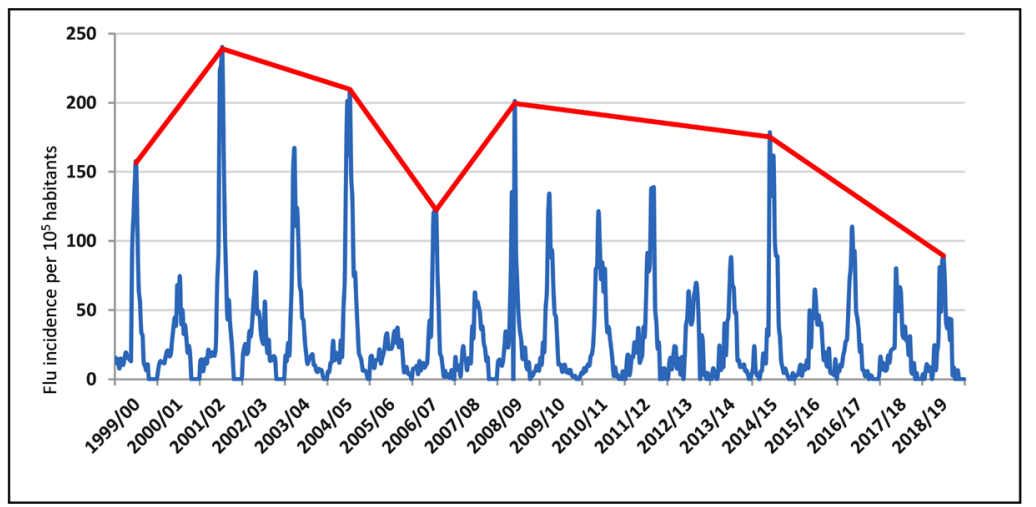

Figure 7. Periodic behaviour I observed in Figure 2.

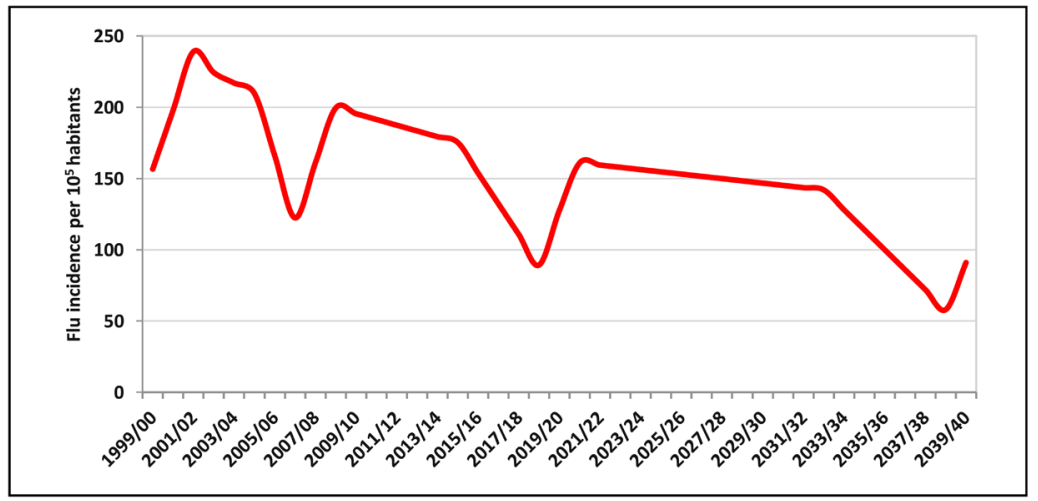

Figure 8. Wave propagation of periodic behaviour I from 1999/2000 to 2039/2040. 


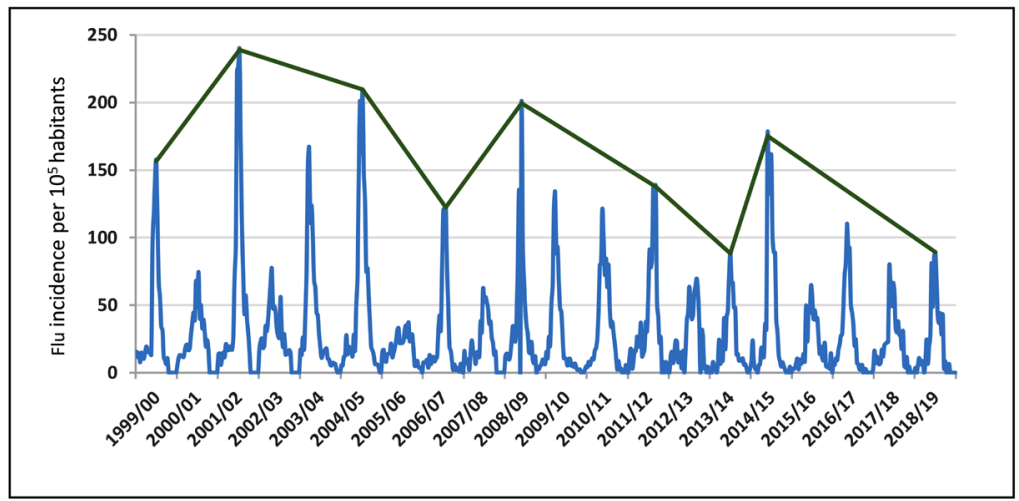

Figure 9. Periodic behaviour II observed in Figure 2.

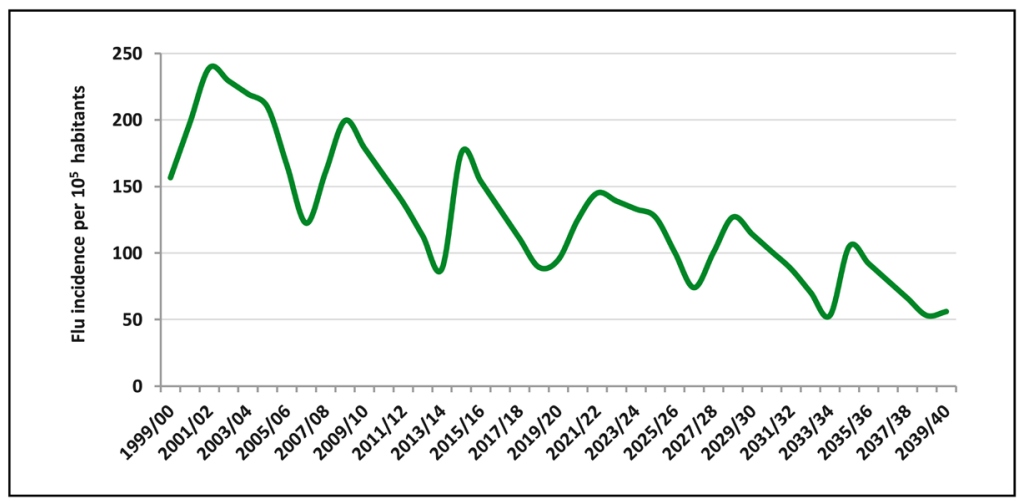

Figure 10. Wave propagation of periodic behaviour II from 1999/2000 to 2039/2040.

the observed trend lines according to some criteria. We also explored periodic behaviour. Despite the fact that the reporting period is relatively short, we were able to derive interesting tendency lines. Overall analysis shows that the flu incidence is decreasing and following these results, the tendency for the next 20 years is continuing to decrease, showing that the measures of prevention and surveillance are working. We believe that our work can contribute to the studies of prevention and control of the flu spread and it can inspire future related works in other geographic areas and also with other epidemic diseases.

\section{Conflicts of Interest}

The authors declare no conflicts of interest regarding the publication of this paper.

\section{References}

[1] Belongia, E.A., Skowronski, D.M., McLean, H.Q., Chambers, C., Sundaram, M.E. and De Serres, G. (2017) Repeated Annual Influenza Vaccination and Vaccine Effectiveness: Review of Evidence. Expert Review of Vaccines, 16, 723-736. https://doi.org/10.1080/14760584.2017.1334554

[2] Allman, E.S. and Rhodes, J.A. (2004) Mathematical Models in Biology: An Introduction. Cambridge University Press, New York.

[3] Hethcote, H.W. (2000) The Mathematics of Infectious Diseases. SIAM Review. 42, 
599-653. https://www.jstor.org/stable/2653135?seq=1\#page_scan_tab_contents https://doi.org/10.1137/S0036144500371907

[4] Plotkin, S. (2014) History of Vaccination. Proceedings of the National Academy of Sciences of the United States of America, 111, 12283-12287.

https://doi.org/10.1073/pnas.1400472111

[5] Barberis, I. Myles, P. Ault, S.K., Bragazzi, N.L. and Martini, M. (2016) History and Evolution of Influenza Control through Vaccination: From the First Monovalent Vaccine to Universal Vaccines. Journal of Preventive Medicine and Hygiene, 57, E115-E120. https://www.ncbi.nlm.nih.gov/pmc/articles/PMC5139605/

[6] WHO (2019) WHO Consultation and Information Meeting on the Composition of Influenza Virus Vaccines for Use in the 2019-20 Northern Hemisphere Influenza Season. 21 February 2019, Beijing, China.

https://www.who.int/influenza/vaccines/virus/recommendations/consultation20190 2/en/indexl.html

[7] Departamento de Doenças Infeciosas. Departamento de Epidemiologia; colab. Direção-Geral da Saúde. Rede Portuguesa de Laboratórios para o Diagnóstico da Gripe (2004-2018). Programa Nacional de Vigilância da Gripe: relatório das épocas 2003/2004-2017/2018. Instituto Nacional de Saúde Doutor Ricardo Jorge. IP. Lisboa. http://www.insa.pt

[8] Instituto Nacional de Saúde Doutor Ricardo Jorge (2009) Boletim de Vigilância Epidemiológica da Gripe.

http://www.insa.min-saude.pt/category/informacao-e-culturacientifica/publicacoes/ atividade-gripal/

[9] Conde, P., Machado, A., Pechirra, P., Rodrigues, A.P., Cristóvão, P., Costa, I., et al. (2015) Efetividade da vacina antigripal entre 2009 e 2015 em Portugal. Boletim Epidemiológico-Observações. 10, 29-32. http://www.insa.pt

[10] Machado A., et al (2019). Vacinação antigripal da população portuguesa nas épocas 2016/2017 e 2017/2018: cobertura e características do ato vacinal. Instituto Nacional de Saúde Doutor Ricardo Jorge. IP. 27 p. http://www.insa.pt

[11] Nunes, B. and Falcão, J.M. (2008) Vacina antigripal cobertura da população portuguesa entre 1998/1999 a 2007/2008. Instituto Nacional de Saúde Doutor Ricardo Jorge. IP. Lisboa. http://www.insa.pt

[12] Departamento de Epidemiologia (2019) Observatório Nacional de Saúde-Instituto Nacional de Saúde Doutor Ricardo Jorge (INSA. IP) (2014-2019). Médicos-Sentinela. Relatório de atividades de 1999-2017. 13-31. Lisboa. http://www.insa.pt 